\title{
Matrix Bondable Antistatic Additives for Fiber Reinforced Thermosets
}

\section{Michaela Gedan-Smolka ${ }^{a *}$, Katrin Schubert, Antje Täger and Hagen Marks}

\author{
Leibniz-Institut für Polymerforschung Dresden, Hohe Str. 6, 01069 Dresden, Germany \\ amgedan@ipfdd.de
}

Keywords: antistatic additives; matrix bondable; SMC; electrolytes; polyelectrolytes.

\begin{abstract}
For electrostatic coating application or for the use in the electronic industry Sheet Molding Composites (SMC) has to be modified antistatically. By a novel approach several organic monomeric and polymeric ionic substances were incorporated into the duromeric bulk phase by covalent bonds in most cases and tested in terms of their antistatic effectiveness. Furthermore the influence of selected additives on the SMC thickening and molding procedure as well as resulting mechanical properties of modified SMC-panels and the powder coating application were studied.
\end{abstract}

\section{Introduction}

Fiber reinforced thermoset materials, such as SMC, are increasingly used in the transportation industry to reduce the overall weight of the structure and so the fuel and energy consumption at the end. The complete vehicle structures in the automotive industry are usually coated electrostatically. For that reason a specific surface resistivity of all substrates $\leq 10^{10} \Omega /$ sq. is required. However, glass fiber reinforced thermosets are insulators with a specific surface resistivity $>10^{12} \Omega / \mathrm{sq}$. For that reason in the state of the art inorganic additives, typically carbon black, are added to the bulk phase, achieving the demanded antistatic behavior [1]. However, there are some drawbacks: carbon black is only mixed physically, not compatible with the organic SMC matrix and so difficult to homogenize. Together with the needed higher amounts to get the antistatic effect the additive can act as a crack initiator resulting in a decrease of the mechanical SMC properties. Furthermore, the SMC color changes from beige to dark grey resulting in limited application of light colors.

The goal of our study was to overcome these drawbacks by a novel approach - the use of organic electrolytes/polyelectrolytes as antistatic additives which are matrix compatible, can be linked chemically into the bulk phase by covalent bonds and not or only slightly colored. This strategy was already found to be successful in wood fiber containing thermosetting composites, such as medium density fiber boards, earlier [2,3]. The synthesis of several polyelectrolytes was described in [4].

\section{Materials}

Unsaturated Electrolytes. (3-Sulfopropyl)-acrylate potassium salt (A4, Aldrich), 1-Allyl-3methyl-imidazoliumchloride (A6, Aldrich), Diallyldimethylammoniumchloride (65 wt.\% solution in $\mathrm{H}_{2} \mathrm{O}$, A7, Aldrich), Sodium-vinylsulfonate (25 wt.\% solution in $\mathrm{H}_{2} \mathrm{O}$, A9, Aldrich).

All ionic substances were used as solids. For the solutions the water was removed by evaporation.

Polyelectrolytes. Poly-(natrium-4-styrolsulfonate) (B1, Aldrich) was used as bought.

Ion containing polyester resins UP9 and UP5 were synthesized via melt condensation according to synthesis routes given in Fig. 1 and Fig. 2.

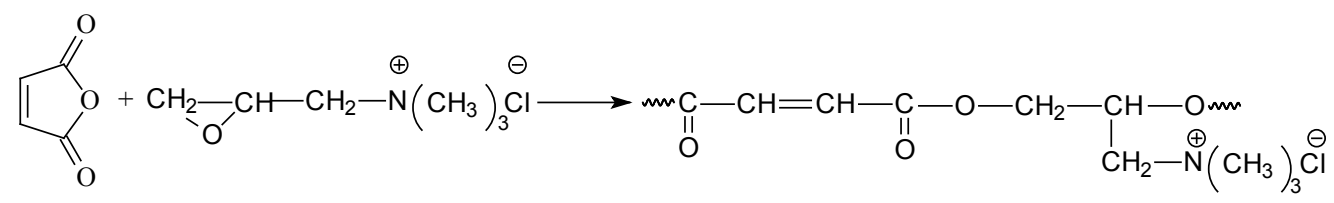

Fig. 1. Synthesis route of ion-containing unsaturated polyester resin UP9 


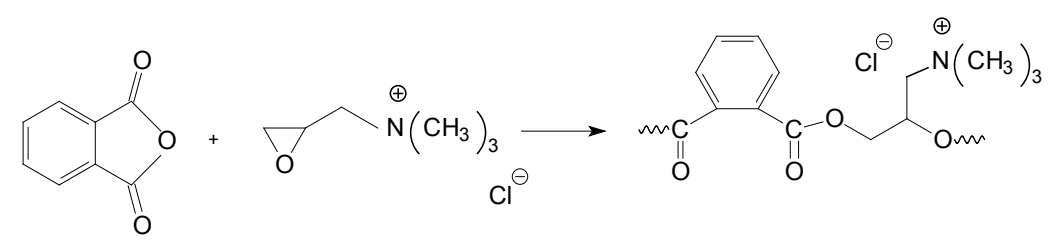

Fig. 2. Synthesis route of ion-containing saturated polyester resin UP5

\section{Methods}

Screening and Percolation Study of Electrolytes/polyelectrolytes. A commercially available mixture of unsaturated polyester resin (Palapreg P18-03V) and styrene was mixed with the required amount of ionic substances by a Dispermat ${ }^{\circledR}$ LC2 (VMA-GETZMANN) at $500 \mathrm{U} / \mathrm{min}$ for $30 \mathrm{~min}$. After adding of peroxy hardeners (Interox TBPEH and Interox TBPEHC) the mixture is once more homogenized for a short time. In the next step the material was applied to glass plate via doctor blade (hight: $0.5 \mathrm{~mm}$ ) and cured at $120^{\circ} \mathrm{C}$ for $30 \mathrm{~min}$. Then the plates were treated by using standard $\left(23{ }^{\circ} \mathrm{C} ; 50 \%\right.$ humidity $)$ or dry climate $\left(20{ }^{\circ} \mathrm{C} ; 35 \%\right.$ humidity) for $16 \mathrm{~h}$ each according to DIN EN ISO 3672-2 [5]. The specific surface resistivity was measured by a HM $307 \mathrm{D}$ (Fetronic) at a test voltage of $100 \mathrm{~V}$ by using a ring electrode (5 positions at the surface, 10 values each).

Preparation of SMC 2 Test Panels. A SMC LP Class A bulk phase material of general formulation as written in [6] was mixed by a Dispermat ${ }^{\circledR}$ LC2 (VMA-GETZMANN) at $500 \mathrm{U} / \mathrm{min}$ for $30 \mathrm{~min}$. Together with a glass fiber mat $(25 \mathrm{wt} . \%)$ instead of cutted fibers a so called "handmade" SMC prepreg mat was prepared. After maturation $\left(23{ }^{\circ} \mathrm{C} / 40 \%\right.$ humidity $)$ for 5 days sheets $(250 \times 120 \times 4 \pm 0.5 \mathrm{~mm})$ were molded at $140{ }^{\circ} \mathrm{C} / 9.5 \mathrm{MPa}$ for $180 \mathrm{~s}$ in a compression molding device (Derek\&Küper).

Rheological Measurements. The Brookfield-viscosity of the SMC-bulk material (no glass fiber content) was performed by a Viscometer DV-II with Heipath Shaft TF $0.5\left(\mathrm{v}=50 \mathrm{U} / \mathrm{min}, 32{ }^{\circ} \mathrm{C}\right.$, measuring time $10 \mathrm{~s}$ ) according to DIN EN ISO 2555 [7]. Dynamic viscosity of the maturated SMC-prepreg mat (2.5 mm thickness) was determined by using an Ares Viscometer (Rheometric scientific) with plate-plate geometry, a frequency of $5 \mathrm{~Hz}$ and a heating rate of $5 \mathrm{~K} / \mathrm{min}$ corresponding to DIN 53018 part 1 [8].

DSC Measurements. The curing reaction of modified SMC was studied by Netzsch-DSC 204 F 1 Phoenix in Al-pans in the temperature range between $20^{\circ} \mathrm{C}$ and $210^{\circ} \mathrm{C}$, heating rate: $10 \mathrm{~K} / \mathrm{min}, 3$ samples each.

Tensile Test. The tensile strength and elongation were carried out by a Zwick 1456 machine according to DIN EN ISO 527-4 by using standard climate conditioned SMC 2 Type 1B dumbbell test specimen (pre-tension force: $1 \mathrm{~N}$, test speed: $2 \mathrm{~mm} / \mathrm{min}, 5$ samples each).

Powder Coating Application. First, commercially available powder coating material (Interpon 610 NE05573-1, AKZO NOBEL) was applied to standard climate conditioned SMC-panels by corona $(60 \mathrm{kV})$. Then the applied powder amount was determined gravimetrically. Finally, the powder was cured in a convection oven $\left(140^{\circ} \mathrm{C} / 25 \mathrm{~min}\right)$. The film thickness was determined by a Positector 200 (DeFelsko, 10 measurements each).

\section{Results and Discussion}

In the first step of this research the antistatic behavior of several low molecular and oligomeric/polymeric ionic substances were tested in the cured matrix components. During homogenization of the various additives was observed that there are completely matrix soluble substances on one hand (A6, UP5, UP9) and, in contrast, less matrix compatible substances which can only be homogenized during mixing, on the other hand. The last additives form visible agglomerates in the cured matrix.

Screening of Antistatic Behavior. The specific surface resistivity of the cured bulk phase in the presence of $5 \mathrm{wt} \% \%$ varies a lot depending on the type of the additive itself and the climate treatment (Fig. 3 a). In comparison to the non-modified matrix the comparable and hygroscopic A 6 exhibits 
the most drastic decrease, nearly independent of the climate. In contrast, the also chemical bondable A7 shows a significant lower, but also significant, effect. The reason for this explicit difference should be an insufficient distribution of the substance and the formation of agglomerates. An addition of the unsaturated oligomer UP9 results in a drastic lowering of the specific surface resistivity but only at standard climate. All the other substances offered almost no effect.

Percolation curves for the low molecular ionic substances showed a percolation threshold for A6 between 2 and 3 wt.\% and A7 at $\sim 9$ wt.\% in the cured matrix. For UP9 the percolation barrier seems to be nearly in the same range as it was determined for A6 (Fig. 3 b).

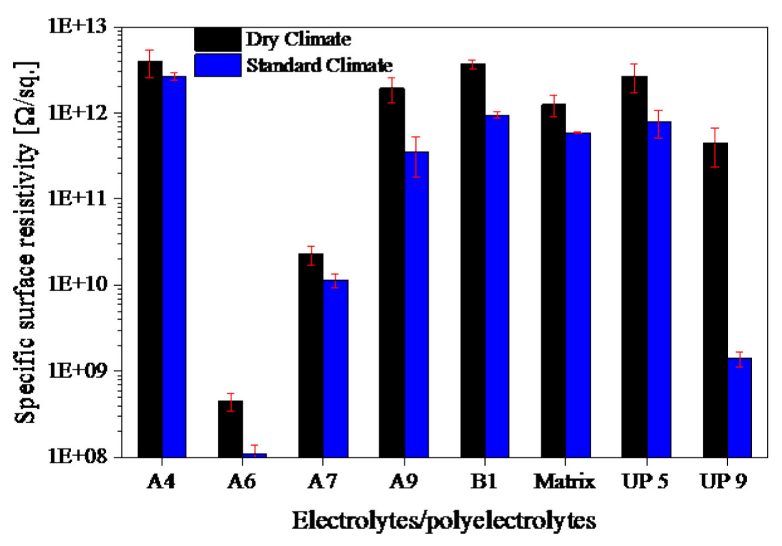

a

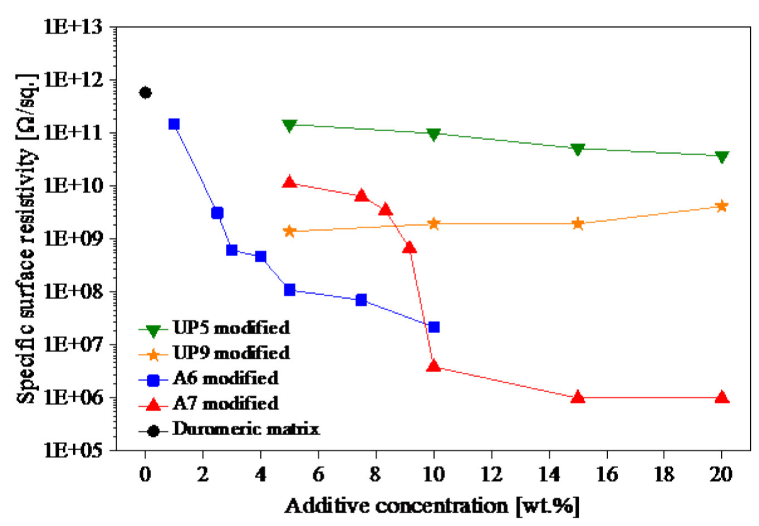

b

Fig. 3. Screening of electrolytes/ polyelectrolytes with regard to their antistatic behavior in an UPresin matrix/additive content: a - 5 wt.\%. Percolation curve of low molecular additives (A 6, A 7) and oligomeric additives (UP5, UP9) in an UP-matrix (b) conditioned in standard climate

Further investigations were carried out by using A6 (5 wt.\%), UP9 (4 wt.\%) and a combination of A6 and UP9 $(0.5+3 \mathrm{wt} . \%)$ in the complete SMC 2 formulation. By doing so the specific surface resistivity $\rho_{\mathrm{S}}$ of molded SMC 2 panels was reduced to values $\leq 1.9 \mathrm{E}+9$ in standard and to values $\leq 9.2 \mathrm{E}+9 \Omega /$ sq. in dry climate. A Combination of both additives led to a synergetic effect opposite to the plain additives each and enables to utilize lower additive amounts.

Influence of Preferred Additives on the SMC Processing and Material Properties. As already described two reactions are important during SMC-panel preparation:

1. The so called "thickening" during maturation resulting in the formation of macro-ions [7].

2. A free radical polymerization between the unsaturated polyester and styrene during molding.

A prerequisite for a successful molding of the SMC mats is a Brookfield viscosity of the SMCbulk phase of $\eta>1 \cdot 10^{8} \mathrm{mPa} \cdot \mathrm{s}$. Except the SMC, modified with A6, all systems reached this value in nearly 5 days. In addition, the initial viscosity in the presence of A6 is much lower. It is assumed that this could be caused by the hygroscopic behavior of the substance (Fig. 4 a).

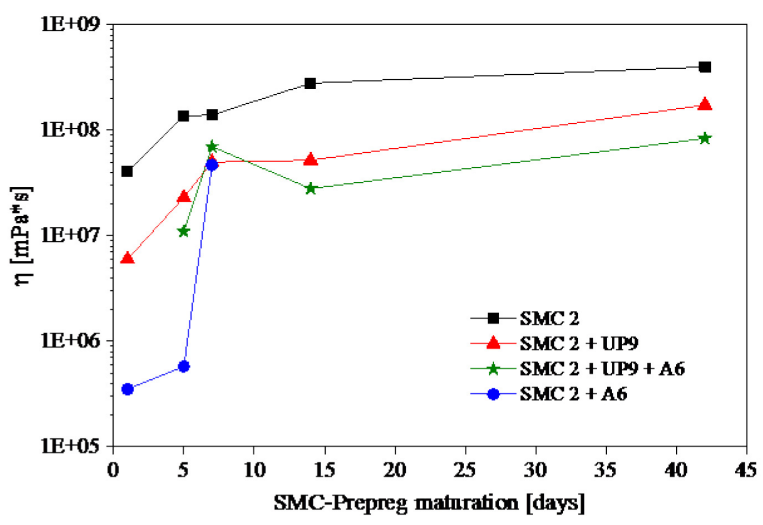

a

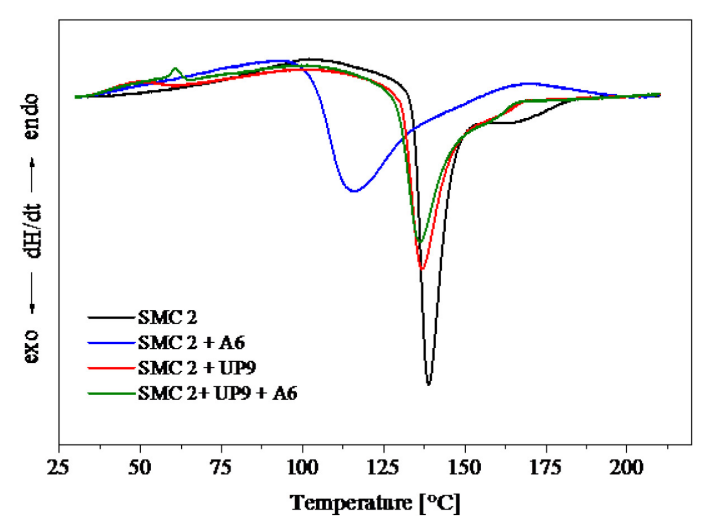

$\mathrm{b}$

Fig. 4. a - influence of the antistatic additives on the SMC-bulk thickening reaction;

$\mathrm{b}$ - the reactivity of the free radical polymerization during molding 
Besides, the reactivity of the maturated SMC sheet is much higher for this material and the reaction temperature maximum is already shifted by $\sim 25^{\circ} \mathrm{C}$ to lower values (Fig. $4 \mathrm{~b}$ ). This behavior is not beneficial because it would require a drastic change in the processing line.

As already expected from the DSC-curves the higher reactivity in the presence of A6 also results in an earlier and higher increase of complex melt viscosity by rheological measurements of the conditioned SMC mat (Fig. 5 a). The integration of UP9 and the combination of both additives lead to lower and acceptable changes of the curve characteristics. The final value of complex viscosity is nearly the same for all samples.

A comparison of resulting mechanical properties of non-modified SMC 2 and additive containing molds (Fig. 5 b) showed almost no differences concerning with the tensile strength, except the material with the low molecular ionic substance A6.

This behavior might be caused by the higher water content in the bulk formulation resulting in elevated amounts of voids and pinholes together with the accelerated curing during molding. In terms of elongation $\varepsilon_{\mathrm{M}}$ no significant difference was observed for all materials.
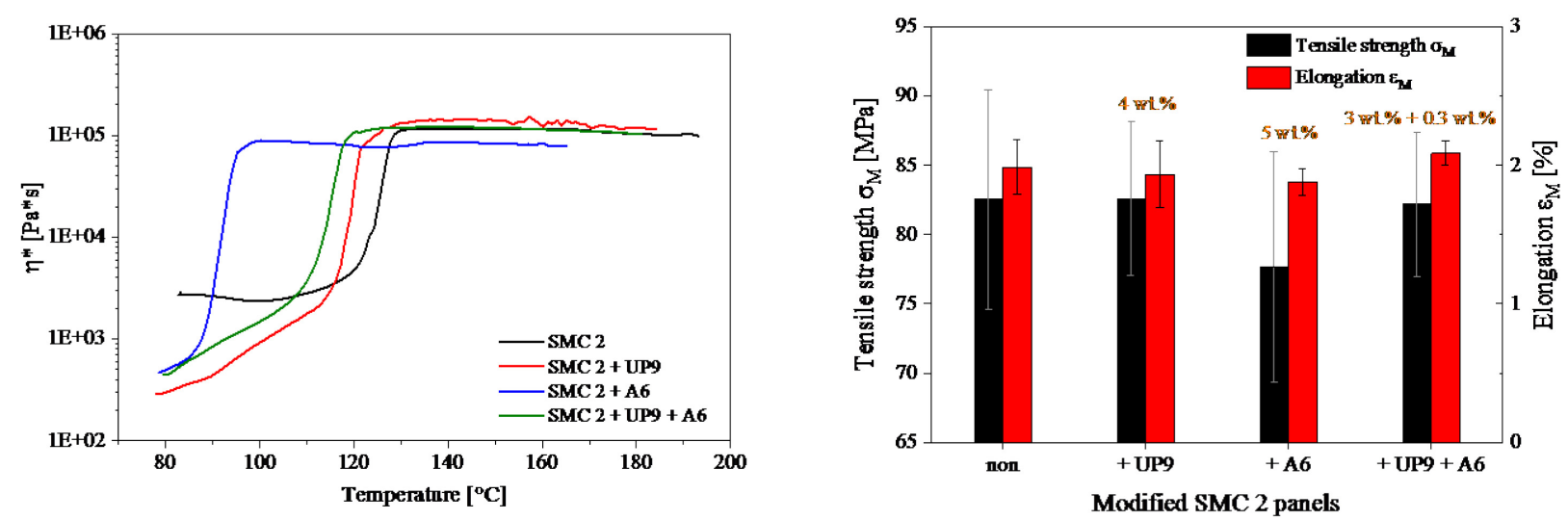

Fig. 5. a - influence of the antistatic additives on the complex viscosity during the free radical polymerization; $b$ - mechanical properties of SMC 2 panels in the cured state
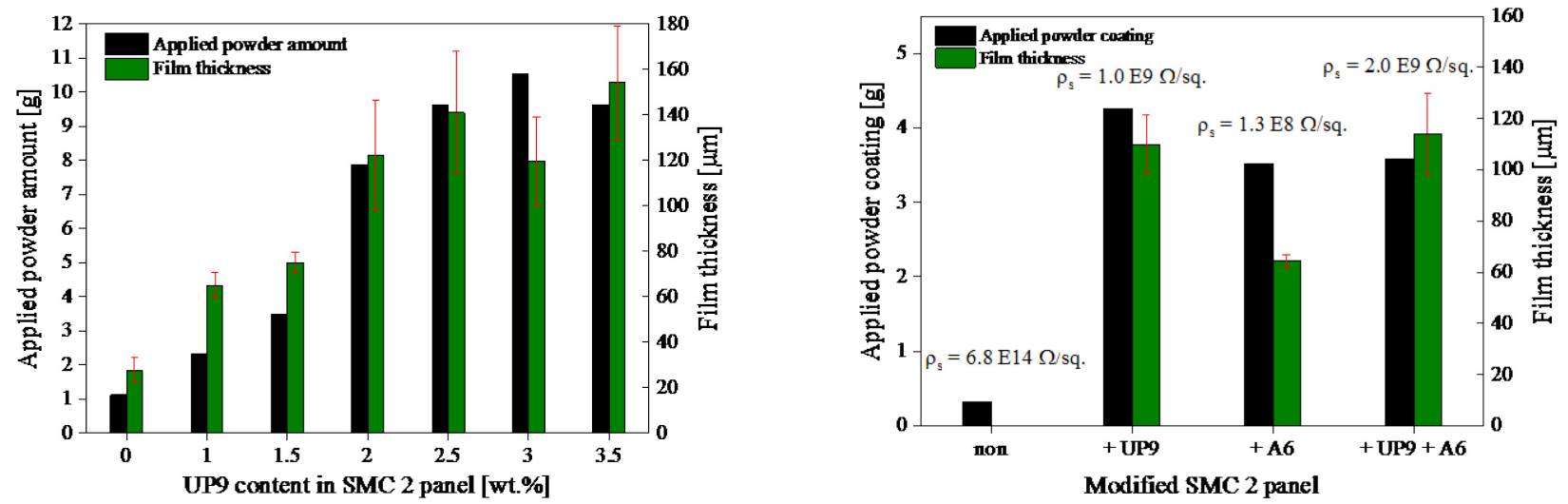

Fig. 6. a - influence of the preferred antistatic additives on the electrostatically applied powder amount and cured film thickness depending on the UP9 content; $b$ - the additive type

Furthermore, a combination of low molecular ionic substance A6 with the oligomeric electrolyte UP9 provided a synergistic effect in terms of lowering the specific surface resistivity. This combination was also proved to be advantageous regarding with the viscosity behavior during the thickening reaction, the reactivity of the free radical polymerization reaction and viscosity behavior during molding. Additionally, the system exhibited nearly the same tensile strength and elongation as observed for the non-modified SMC.

Finally, successful powder coating application tests proved the novel approach for the antistatic treatment of SMC-materials. 


\section{Acknowledgements}

The authors thank Mr. Kuehfusz and Ms. Rebel (Polytec GmbH Gochsheim) for the donation of SMC-Class A material and the opportunity to test the additives in the SMC-recipe during a research placement in the company. In addition, we thank Mr. Scheibner for the mechanical testing. Furthermore, the authors are grateful the German Federal Ministry of Education and Research (BMBF 01 RI 0631 B) for funding.

\section{References}

[1] R.G. Charles, Conductive molding compositions and articles therefrom, WO 00/49076, 1999.

[2] A. Taeger, M. Gedan-Smolka, B. Lilie, D. Krug, Polymere Antistatikadditive für Holzwerkstoffe, Holztechnologie. 52 (2011) 23-27.

[3] A. Taeger, M. Gedan-Smolka, M. Tuschla, D. Lehmann, IPF Dresden, Beschichtung für Holzmaterialien und Verfahren zu ihrer Herstellung, DE 10806 (2009) 2007000.

[4] K. Schubert, M. Gedan-Smolka, Synthesis and characterization of new oligomeric/polymeric antistatic additives for sheet molding composites, J. Appl. Polym. Sci, 134 (2017) 44741.

[5] DIN EN ISO 3672-2: Ungesättigte Polyesterharze, Herstellung von Probekörpern und Bestimmung von Eigenschaften; Berlin: Beuth Verlag 2002.

[6] M. Gedan-Smolka, A. Müller, U. Gohs, A. Calvimontes, Electron pretreatment of sheet molding compounds (SMC), Progress in Organic Coatings. 72 (2011) 159-167.

[7] DIN EN ISO 2555: Harze im flüssigen Zustand, als Emulsionen oder Dispersionen, Bestimmung der scheinbaren Viskosität nach dem Brookfield-Verfahren; Berlin: Beuth Verlag, 1999.

[8] DIN 53018 Teil 1: Messung der dynamischen Viskosität newtonscher Flüssigkeiten mit Rotationsviskosimetern; Berlin: Beuth Verlag, 1976.

[9] M. Gruskiewicz, J. Collister, Analysis of the thickening reaction of a sheet molding compound resin through the use of dynamic mechanical testing, Polym. Composites. 1 (1982) 6-11. 